\title{
THE GENETIC CONTROL OF LEAF DEVELOPMENT IN LOLIUM
}

\section{RESPONSE TO SELECTION}

\author{
K. J. R. EDWARDS and J. P. COOPER \\ Welsh Plant Breeding Station, Aberystwyth
}

\section{INTRODUCTION}

Received 30.i.63

ONE of the main factors controlling dry matter production in grasses, as in other crops, is the total area of leaf surface available for interception and utilisation of the incoming light energy. The rate at which plants accumulate leaf area is particularly important during seedling growth, or following severe defoliation, in order to ensure the rapid attainment of a complete ground cover with the concomitant interception of all the incident light.

The first paper of this series (Cooper and Edwards, 196I) reported an assessment of (i) the genetic variation within three populations of ryegrass for a number of characters associated with seedling leaf development, and (ii) genetic correlations between characters. This assessment was obtained from a progeny test which provided estimates of heritabilities and of genetic correlations between characters. Although the samples were small, the results showed large differences between families and suggested that appreciable additive genetic variation existed within the populations for these seedling characters in most cases. At the same time, negative genetic correlations were detected between leaf size and rate of leaf appearance and between tiller number per plant and individual tiller weight.

Estimates of heritabilities and genetic correlations for a population can be used to predict the responses, both direct and correlated, to directional selection for a character within that population. But the actual responses obtained may differ from those predicted either because of sampling error or because the process of selection itself changes the genetic situation. For the latter reason, and assuming that the population size is large enough to avoid genetic drift, a heritability estimate applies strictly only to the generation for which it was estimated and, theoretically, can be used to predict the results of only one generation of selection. Beyond this, changes in gene frequencies and the production of new genotypes will alter the genetic situation. This may well result in a changed heritability and, therefore, a different potential response to selection in the following generation. The same limitations apply to the use of genetic correlations in predicting correlated responses. In practice, however, a linear response 
is often maintained over several generations, say five or ten (Clayton, Morris and Robertson, 1957).

Selection may thus give additional information about the genetic control of a character, or group of characters, within a population from a study of direct and correlated responses. Results from selection experiments and progeny tests will be complementary. Therefore, following the progeny test reported in the earlier paper, selection has been made for both high and low expression of individual leaf size and of rate of leaf appearance. These lines have now reached the third generation and the results they provide are presented and discussed in this paper.

\section{MATERIALS AND METHODS}

Selection for both individual leaf size and rate of leaf appearance was carried out in two varieties of perennial ryegrass, Irish and Hunsballe, and selection for leaf size only was also made in Italian ryegrass. The lines selected for leaf size were developed from the progeny test reported in the previous paper, these families being regarded as the first generation of selection because their parents had been selected and mated assortatively for leaf size. The lines selected for rate of leaf appearance were developed independently of those selected for leaf size but from the same basic stocks of the two varieties concerned. With the second generations of all lines the basic stocks were used as controls; with the third generations new stocks had to be used, but these were obtained from the same seeds firm.

\section{Mating Systems}

At each generation of selection within each line, four plants were selected as parents to produce the next generation. In the leaf size selection lines the two most extreme families (either for high or low leaf size) within each variety were selected and from each of these the two most extreme plants were picked out. These four plants were isolated and allowed to interpollinate to produce the second generation. From this, in turn, the four most extreme plants were selected and mated in pairs to produce two lines for each direction of selection within each variety at the third generation. In the rate of leaf appearance lines, on the other hand, a regular system of double first-cousin mating was used, again selecting four parents at each generation. This resulted in rather less inbreeding than the system used in the leaf size selection lines, the theoretical inbreeding coefficient being calculated at $0 \cdot 125$ as opposed to $0 \cdot 203$.

\section{Experimental details}

All the experiments were performed in glasshouses with the seedlings grown in soil, in boxes, at a standard density (a spacing of $2 \times 2 \frac{1}{2}$ ins.). All the experiments used a randomised block layout with four replications and eight plants of each line per replicate. The harvest data for all the third generation lines, however, were collected from only three of the four replicates. Three separate experiments were sown on the following dates :

(i) 23rd January 1959: Second generation of selection for rate of leaf appearance.

(ii) I gth August 1959: Second generation of selection for leaf size.

(iii) I Ith August 1960: Third generation of all lines.

The characters recorded were the same as those listed in the first paper of the series and are expressed in the same units, with the exception that rate of leaf appearance is now expressed in leaves per day rather than days per leaf, although 
it is still calculated from the same basic measurement which is the interval in days between the appearance of the fourth and seventh leaves on the main shoot. The harvests from which shoot weights, tiller weights and tiller number per plant were recorded, were all taken at approximately the mean date at which the eighth leaf on the main shoot appeared in each particular experiment.

\section{Analysis of data}

Within each generation and each variety, and for each character, the results from the various lines and populations were treated by a conventional analysis of variance to test the significance of differences between lines.

The realised heritabilities were calculated from the formula :

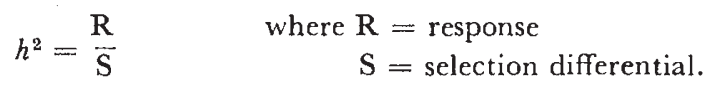

The response (R) was measured as the difference between the lines selected in opposite directions. If there were two lines in a particular direction the mean of the two was used. The selection differential (S) has been taken as the deviation of the mean of the selected parents from the mean of the population from within which the selections were made. A cumulative selection differential was obtained by summing the differentials for the individual generations and adding together the results for both directions of selection. As the measurements of responses and differentials were made in different years, an attempt has been made to standardise them by dividing each response or differential by the appropriate standard deviation.

Realised genetic correlations have been calculated according to the formula given by Falconer (1960):

where

$$
r_{\mathrm{A}}=\frac{\mathrm{CR}_{y} h_{x} s_{x}}{\mathrm{R}_{x} h_{y} s_{y}}
$$

$$
\begin{aligned}
\mathrm{R}_{x} & =\text { direct response in character } x \\
\mathrm{CR}_{y} & =\text { correlated response in character } y \\
h_{x} & =\sqrt{h^{2}} \text { character } x \\
h_{y} & =\sqrt{h^{2}} \text { character } y \\
s_{x} & =\text { standard deviation of character } x \\
s_{y} & =\text { standard deviation of character } y
\end{aligned}
$$

Both direct and correlated responses have been measured as the differences between the high and low line means for the appropriate characters.

\section{RESULTS}

(a) Direct responses

The means of the various selection lines for both second and third generations, compared with the unselected varieties, are shown in tables $I$ and 2. The least significant differences refer to comparisons of the sclection line means with the unselected control, Realised heritability estimates are also shown for each variety in each generation. A comparison of these realised estimates with the original heritability estimates reported in the earlier paper appears in table 5 .

(i) Leaf size. Table I shows the results for direct response to sclection for leaf size in both directions. After two generations, in Italian there were large and significant responses in both the high and low lines, which were symmetrically spaced around the control. The realised heritability was high, 0.82 , compared to the value of $0.4 \mathrm{I}$ estimated from the progeny test reported in the earlier paper. 
After a further generation of selection, however, the response has not increased, with the result that the realised heritability has fallen to 0.39 . At this third generation the response appears to be asymmetrical about the control, the high line being no higher than the control. But this may not be a true asymmetry for in this generation the control population was not a sample of the initial stock. The

TABLE I

Direct response to selection for leaf size $\left(\mathrm{mm} .^{2}\right)$

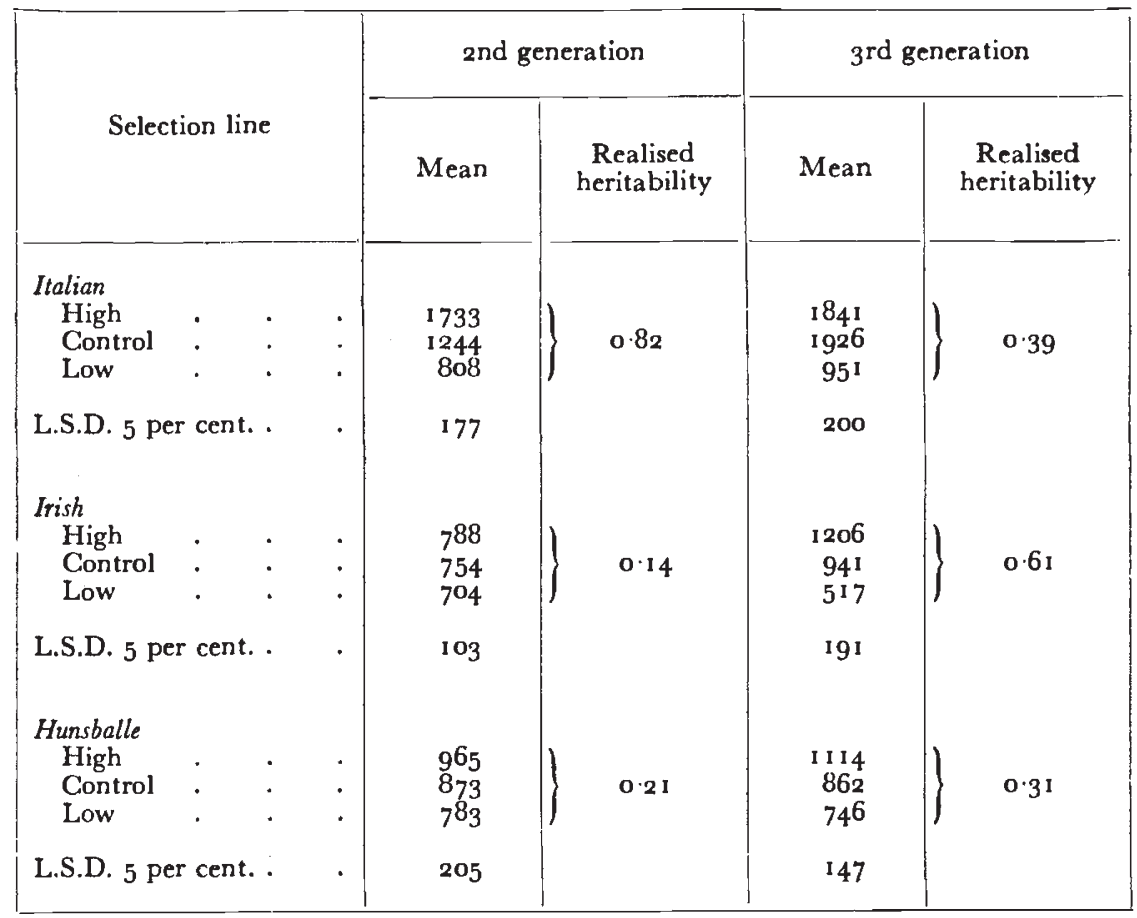

Least significant differences in this and all other tables refer to comparisons between the control mean and either the high or low line mean.

original material was used as a control in the second generation experiment when it had a mean leaf size of $1244 \mathrm{~mm} .{ }^{2}$, intermediate between the high and low lines.

In Irish, the second generation shows that a very slight and nonsignificant response has occurred, with a realised heritability of only $0 \cdot 14$, agreeing well with the original estimate of $0 \cdot 18$. At the third generation, however, a sudden and very large response has appeared in both directions giving a realised heritability of $0.6 \mathrm{I}$.

In Hunsballe, selection has produced a steady response with realised heritabilities in both second and third generations which agree well with the original estimate of $0 \cdot 26$.

The variances within lines and populations fluctuated considerably, 
there being no consistent trend either between high and low lines or between selected and control populations.

(ii) Rate of leaf appearance. Table 2 presents the results of selection for rate of leaf appearance. In Irish there has been considerable response in both directions after only two generations. This rapid response is continued in the third generation at which stage the high line is producing leaves at twice the rate of the low.

Selection within Hunsballe has produced a smaller response than in Irish. The realised heritabilities for the second and third generations were 0.69 and 0.27 respectively, compared to the original estimate of

TABLE 2

Direct response to selection for rate of leaf appearance (leaves per week)

\begin{tabular}{|c|c|c|c|c|c|}
\hline \multirow{2}{*}{\multicolumn{2}{|c|}{ Selection line }} & \multicolumn{2}{|c|}{ 2nd generation } & \multicolumn{2}{|c|}{$3^{\text {rd }}$ generation } \\
\hline & & Mean & $\begin{array}{c}\text { Realised } \\
\text { heritability }\end{array}$ & Mean & $\begin{array}{c}\text { Realised } \\
\text { heritability }\end{array}$ \\
\hline \multicolumn{6}{|l|}{ Irish } \\
\hline High & . & $1 \cdot 30$ & & $1 \cdot 30$ & \\
\hline Control & . & 1.09 & 0.77 & 0.93 & 0.65 \\
\hline Low & . & 0.99 & & 0.54 & \\
\hline L.S.D. 5 pe & cent. & 0.08 & & 0.08 & \\
\hline \multicolumn{6}{|l|}{ Hunsballe } \\
\hline High & . & $1 \cdot 16$ & & 0.97 & \\
\hline Control & . & $1 \cdot 12$ & 0.69 & 0.90 & 0.27 \\
\hline Low & . & 1.02 & & 0.64 & \\
\hline L.S.D. 5 pe & cent. . & 0.03 & & 0.11 & \\
\hline
\end{tabular}

$0 \cdot 62$. There appears to be some asymmetry in both generations, with the high line being only slightly faster than the control.

As for the leaf size selection lines, the variances within lines and populations in the rate of leaf appearance selection experiments fluctuate irregularly and are not presented.

The means, including the control, for rate of leaf appearance are generally lower when the third generation lines were grown in the I 960 experiments than in the 1959 experiment. This is almost certainly due to the former having been conducted in the autumn in an unheated glasshouse and the latter in the spring in a heated glasshouse.

\section{(b) Correlated responses}

These are shown in tables 3 and 4 , which present the means for seven characters after three generations of selection for either lcaf size or rate of leaf appearance. When comparing the selected lines 
with the control populations, the different origin of the control population must be remembered.

(i) Selection for leaf size (table 3). Within both Italian and Irish the responses in leaf size have occurred as a result of changes in both length and width of leaves, but in Hunsballe the change has been mainly in leaf width. The effect of selection for leaf size on rate of

TABLE 3

Correlated response to selection for leaf size: 3 rd generation

\begin{tabular}{|c|c|c|c|c|c|c|c|c|}
\hline \multicolumn{2}{|c|}{$\begin{array}{l}\text { Selection } \\
\text { line }\end{array}$} & $\begin{array}{c}\text { Leaf } \\
\text { size } \\
\left(\mathrm{mm} .{ }^{2}\right)\end{array}$ & $\begin{array}{c}\text { Leaf } \\
\text { length } \\
\text { (mm.) }\end{array}$ & $\begin{array}{l}\text { Leaf } \\
\text { width } \\
(\mathrm{mm} .)\end{array}$ & $\begin{array}{l}\text { Rate of leaf } \\
\text { appearance } \\
\text { (Ivs./week) }\end{array}$ & $\begin{array}{c}\text { Tiller } \\
\text { no. }\end{array}$ & $\begin{array}{c}\text { Tiller } \\
\text { wt. } \\
\text { (mgm.) }\end{array}$ & $\begin{array}{c}\text { Plant } \\
\text { wt. } \\
\text { (gm.) }\end{array}$ \\
\hline \multicolumn{9}{|l|}{ Italian } \\
\hline High & . & $184 \mathrm{I}$ & 276 & $6 \cdot 58$ & 0.44 & II $\cdot 9$ & 75 & 0.90 \\
\hline Control & . & 1926 & 296 & $6 \cdot 45$ & 0.74 & 19.7 & 66 & $1 \cdot 24$ \\
\hline Low. & . & $95^{1}$ & 204 & $4: 59$ & 0.70 & 14.3 & 39 & 0.56 \\
\hline L.S.D. 5 pe & cent. & 200 & 26 & 0.52 & $0 \cdot 13$ & $3 \cdot 6$ & 12 & 0.20 \\
\hline \multicolumn{9}{|l|}{ Irish } \\
\hline High & . & 1206 & 253 & $4 \cdot 69$ & 0.82 & $19 \cdot 1$ & 45 & 0.86 \\
\hline Control & . & $94^{\mathrm{I}}$ & 230 & 4.04 & 0.93 & $25 \cdot 0$ & 39 & $0 \cdot 96$ \\
\hline Low . & . & 517 & 149 & $3 \cdot 37$ & 0.98 & $23 \cdot 1$ & 20 & $0 \cdot 4^{6}$ \\
\hline L.S.D. 5 pe & cent. & 191 & 33 & $0 \cdot 36$ & 0.11 & $5 \cdot 7$ & 7 & $0 \cdot 26$ \\
\hline \multicolumn{9}{|l|}{ Hunsballe } \\
\hline High & . & $\mathrm{III}_{4}$ & 223 & 4.95 & $0 \cdot 71$ & $14^{-I}$ & 43 & $0 \cdot 63$ \\
\hline Control & . & 862 & 221 & 3.85 & $0.9^{\circ}$ & $20 \cdot 2$ & 37 & 0.73 \\
\hline Low. & . & $74^{6}$ & 202 & $3 \cdot 60$ & 0.88 & $18 \cdot 2$ & $3^{8}$ & 0.70 \\
\hline L.S.D. $5 \mathrm{pe}$ & cent. & 147 & 27 & 0.35 & 0.12 & $3 \cdot 0$ & 8 & 0.20 \\
\hline
\end{tabular}

leaf appearance is to produce a negative response, the high leaf size lines having a slower rate of appearance than the low.

Changes in tiller number per plant are similar to those for rate of leaf appearance, as might have been expected. Changes in tiller weight show that in both Italian and Irish changes have occurred which are positively and strongly correlated with the directional selection for leaf size; in Hunsballe the correlation is also positive but is only slight.

The effects of selection for leaf size on plant weight are rather complex. In Italian, and also in Irish, the high line is heavier than the low, but the control population is heavier than either. In Hunsballe neither the high nor the low line differs significantly from the control.

(ii) Selection for rate of leaf appearance (table 4). In Irish there has occurred a very large negative response in leaf size which is associated with negative changes in both leaf length and width. In Hunsballe, on the other hand, there is only a very slight and non-significant 
negative response in leaf size, although the change in leaf width is negative and barely significant.

Tiller number in Hunsballe shows no correlated response, and in Irish the positive correlation is barely significant. In ryegrass in general, tiller number is strongly correlated with rate of leaf appearance, but in the present case the lack of any such strong positive correlation may be due to a delay in the initial onset of tillering in the lines selected for high rate of leaf appearance. In Irish, for example, only i 2 per cent. of plants in the high line produced a side tiller in the axil of the

TABLE 4

Correlated responses to selection for rate of leaf appearance: 3 rd generation

\begin{tabular}{|c|c|c|c|c|c|c|c|}
\hline $\begin{array}{l}\text { Selection } \\
\text { line }\end{array}$ & $\begin{array}{l}\text { Rate of leaf } \\
\text { appearance } \\
\text { (lvs./week) }\end{array}$ & $\begin{array}{c}\text { Leaf } \\
\text { size } \\
\left(\mathrm{mm} .{ }^{2}\right)\end{array}$ & $\begin{array}{l}\text { Leaf } \\
\text { length } \\
\text { (mm.) }\end{array}$ & $\begin{array}{r}\text { Leaf } \\
\text { width } \\
\text { (mm.) }\end{array}$ & $\begin{array}{c}\text { Tiller } \\
\text { no. }\end{array}$ & $\begin{array}{c}\text { Tiller } \\
\text { wt. } \\
\text { (mgm.) }\end{array}$ & $\begin{array}{l}\text { Plant } \\
\text { wt. } \\
\text { (gm.) }\end{array}$ \\
\hline \multicolumn{8}{|l|}{ Irish } \\
\hline High . & I. 30 & $3^{62}$ & 127 & $3 \cdot 02$ & $2 I \cdot I$ & $2 \mathrm{I}$ & 0.43 \\
\hline Control & 0.93 & $94 \mathrm{I}$ & 230 & 4.04 & 25.0 & $\begin{array}{l}39 \\
28\end{array}$ & 0.95 \\
\hline Low. & 0.54 & 724 & 170 & $4 \cdot 10$ & $16 \cdot 9$ & 28 & $0.4^{6}$ \\
\hline L.S.D. 5 per cent. & 0.08 & 192 & 32 & 0.55 & $4^{\cdot I}$ & II & 0.32 \\
\hline \multicolumn{8}{|l|}{ Hunsballe } \\
\hline High & 0.97 & 947 & 229 & $\begin{array}{l}3.99 \\
2.85\end{array}$ & $18 \cdot 0$ & 44 & 0.80 \\
\hline Control & 0.90 & 862 & $22 \mathrm{I}$ & 3.85 & $20 \cdot 2$ & 37 & 0.73 \\
\hline Low & 0.04 & 970 & 215 & $4 \cdot 35$ & 180 & $4^{6}$ & 0.93 \\
\hline L.S.D. 5 per cent. & $0 \cdot I I$ & 128 & 20 & $0.3 \mathrm{I}$ & 5.0 & IO & 0.32 \\
\hline
\end{tabular}

coleoptile, whereas in the low line 87 per cent. of the plants did so. The corresponding figures for Hunsballe were 52 and 72 per cent. These differences tend to mask the high rate of tiller production that one expects to find associated with a high rate of leaf production.

Tiller weight and plant weight show no trends associated with selection for rate of leaf appearance, but in Irish both high and low lines have significantly lower plant weights than the control.

Some of the correlated responses after three generations are expressed as realised genetic correlations in table 5, where they are compared with the original estimates of these correlations. This shows in all cases the negative response in either leaf size or rate of leaf appearance when selection is made for one extreme of the other character. Selection for leaf size in all three varieties has been associated positively with changes in tiller weight. The positive correlations between leaf size and plant weight in both Italian and Irish are misleading because they ignore the fact that all the selection lines in these two varieties had lower plant weights than the control. In general, selection for either leaf size or rate of leaf appearance has not improved plant weight. 


\section{DISCUSSION}

In the first paper of this series (Cooper and Edwards, op cit.) the heritability estimates obtained from a progeny test for seedling characters were discussed in relation to the nature of the characters and to the known selection histories of the populations. In general, the values obtained were less than those for date of ear emergence in Lolium (Cooper, 1959a, b, c) which were greater than 0.7. But date of ear emergence is primarily a response to a particular photoperiod, an environmental factor which is completely regular and predictable. These seedling characters, on the other hand, are more likely to be affected by changes in many environmental factors and will be expected to show greater environmental variance. But heritabilities were generally large enough to be statistically significant, despite the large sampling errors. It was concluded that considerable additive genetic variation existed within these populations for various seedling characters, particularly rate of leaf appearance and leaf dimensions. It now remains to see whether the results obtained from direct selection substantially alter this picture.

The realised heritability values obtained from selection for leaf size in both Italian and Hunsballe agree well with the original estimates. But in Irish the realised heritability is much higher, this difference in fact occurring as a result of a sudden and very large response to selection in the third generation, the reasons for which are not known. Linkage and drift could be contributing factors, but it is remarkable that the sudden response appears to have occurred simultaneously in both high and low lines.

Whereas realised heritabilities for leaf size showed good agreement with the original estimates or were larger, those for rate of leaf appearance were lower in both Irish and Hunsballe, particularly at the third generation. The reasons for this fall are not clear, but it must be remembered that the original estimates were obtained from one set of samples of the populations while the selection lines were initiated from another set. As the samples in each case were small, sampling error and genetic drift may well account for the differences between the estimates. Genotype-environment interaction may also be important, for the second generation was grown in spring and the third in autumn. Thus the changes observed in heritability estimates should not be regarded as good indications of changes in the amounts of additive genetic variance.

In general, therefore, the results of selection for leaf size and rate of leaf appearance confirm the conclusion that considerable additive genetic variation was present for these characters in the basic populations. But beyond this rather broad generalisation about the basic populations, other inferences can be made only very cautiously because of the small size of the initial sample (sixteen plants) and the selection of only four plants within each line at each generation. Under these conditions genetic drift is likely to be important and to 
cause changes which will be unpredictable in direction. The size of such changes (that is, the change of the mean) will also be unpredictable, depending on the number of genes involved, gene frequencies and type of gene action. For none of the characters under direct selection has drift been large enough to prevent a direct response occurring, but it may well account for differences between realised heritabilities and the original estimates.

Similarly, differences between realised genetic correlations and

TABLE 5

Comparison of realised and original estimates of heritabilities and genetic correlations after three generations of selection

\begin{tabular}{|c|c|c|c|c|c|c|}
\hline \multirow[b]{3}{*}{$\begin{array}{l}\text { Heritabilities } \\
\text { Leaf size } \cdot \\
\text { Rate of leaf appearance }\end{array}$} & \multicolumn{2}{|c|}{ Italian } & \multicolumn{2}{|c|}{ Irish } & \multicolumn{2}{|c|}{ Hunsballe } \\
\hline & Realised & Original & Realised & Original & Realised & Original \\
\hline & $\begin{array}{c}\text { o.39 } \\
\ldots\end{array}$ & $\begin{array}{c}0.41 \\
\ldots\end{array}$ & $\begin{array}{l}0.6 \mathrm{I} \\
0.65\end{array}$ & $\begin{array}{l}0 \cdot 18 \\
1 \cdot 16\end{array}$ & $\begin{array}{l}0 \cdot 31 \\
0 \cdot 27\end{array}$ & $\begin{array}{l}0.26 \\
0.62\end{array}$ \\
\hline Genetic correlations & & & & & & \\
\hline $\begin{array}{l}\text { Leaf size } \times \text { rate of leaf } \\
\text { appearance }\end{array}$ & -0.73 & -0.25 & $-0 \cdot 46$ & -0.17 & $-0 \cdot 94$ & $-0 \cdot 19$ \\
\hline Leaf size $\times$ tiller weight & +0.73 & +0.99 & $+1 \cdot 11$ & +0.65 & $+0 \cdot 4^{0}$ & +0.75 \\
\hline Leaf size $\times$ plant weight & +0.42 & $\ldots$ & +0.90 & $\therefore$ & -0.17 & ... \\
\hline $\begin{array}{l}\text { Rate of leaf appearance } \\
\quad \times \text { leaf size }\end{array}$ & $\ldots$ & $\cdots$ & -0.42 & -0.17 & -0.05 & $-0 \cdot 19$ \\
\hline $\begin{array}{l}\text { Rate of leaf appearance } \\
\times \text { leaf length }\end{array}$ & $\cdots$ & $\cdots$ & $-0 \cdot 34$ & -0.43 & +0.23 & $-0 \cdot 74$ \\
\hline $\begin{array}{l}\text { Rate of leaf appearance } \\
\times \text { leaf width }\end{array}$ & $\cdots$ & $\cdots$ & $-0 \cdot 50$ & $+0 \cdot 3^{8}$ & -0.21 & $+0 \cdot 11$ \\
\hline $\begin{array}{l}\text { Rate of leaf appearance } \\
\times \text { tiller number }\end{array}$ & $\cdots$ & $\ldots$ & $+0 \cdot 13$ & $+0 \cdot 61$ & +0.01 & +0.67 \\
\hline $\begin{array}{l}\text { Rate of leaf appearance } \\
\times \text { plant weight }\end{array}$ & $\ldots$ & $\ldots$ & -0.09 & $\cdots$ & -0.11 & $\ldots$ \\
\hline
\end{tabular}

The first-named character in each pair for genetic correlations is that for which direct selection has been made.

the original estimates may be due to drift. But in the case of the association of leaf size and rate of leaf appearance the realised genetic correlations are in general much more strongly negative than were the original estimates, as can be seen from table 5 . This general trend suggests a real effect of selection rather than a random one; but this may not be so, because genetic correlation coefficients have large sampling errors. It is sufficient here to note that the selection experiments have confirmed the existence of negative genetic correlations between these two characters in all three varicties.

While the use of small samples severely limits the generalisation which can be made about the populations from which they were taken, one conclusion can clearly be drawn about the samples themselves. 
This is that the initial plants were very probably heterozygous, or at least heterogeneous, for many of the genes controlling each of the two main characters. This is apparent from the rapid responses which have occurred, and in particular because of the large divergences which have been produced between high and low lines which both began from the same small initial number of plants. The very large response which has occurred for rate of leaf appearance in Irish suggests that much of the variation may be due to segregation of a few genes with relatively large effects.

The failure of selection for either high leaf size or high rate of leaf appearance to increase plant weight has developmental implications. The negative correlations between these two leaf characters appear to be due to developmental interactions between them, and evidence will be presented in a later paper to show that competition exists between them for supplies of substrates. This emphasises the point that in studies of economic yield and its components an approach combining developmental and quantitative genetics should be used.

\section{SUMMARY}

Selection was made for both extremes of individual leaf size aild rate of leaf appearance at the seedling stage within some varieties of ryegrass.

Realised heritabilities were calculated from the responses to such directional selection. These responses were in all cases large, and were sufficient to produce considerable and significant differences between the lines selected in opposite directions after only 3 generations. The realised heritability estimates in general agreed fairly well with estimates made earlier from a progeny test, and confirmed the conclusion that considerable additive genetic variation was present for these two seedling characters within the populations sampled.

Calculated realised genetic correlations showed that in all three varieties there was a marked negative association between leaf size and rate of leaf appearance. Selection for a high expression of one caused a reduction in the other. While this may have been due in part to random effects or to the inbreeding associated with the experiment, it is postulated that competition for available substrates between the basic developmental processes underlying these two characters is a major cause.

Thus while there was sufficient additive genetic variation present to permit rapid response to selection, negative correlations between the characters nullified any increase in the total leaf area or weight of the plant.

\section{REFERENCES}

Cl.Ayton, G. A., MORRIS, J. A. AND ROBERTSON, A. 1957. An experimental check on quantitative genetical theory. I. Short-term responses to selection. $\mathcal{J}$. Geret., 55, 131-151. 
COOPER, J. P. 1959a. Selection and population structure in Lolium. I. The initial populations. Heredity, 13, 31 7-340.

COOPER, J. P. I959b. Selection and population structure in Lolium. II. Genetic control of date of ear emergence. Heredity, 13, 445-459.

COOPER, J. P. I959c. Selection and population structure in Lolium. III. Selection for date of ear emergence. Heredity, 13, 46 I-479.

COOPER, J. P. AND EDWARDS, K. J. R. I96I. The genetic control of leaf development in Lolium. I. Assessment of genetic variation. Heredity, 16, 63-82.

FALCONER, D. s. 1960. Introduction to Quantitative Genetics. Oliver and Boyd, Edinburgh, pp. 365 . 